\title{
GENETICS
}

\section{Genes and equality}

C Farrelly

J Med Ethics 2004;30:587-592. doi: 10.1136/jme.2002.002329

The way people think about equality as a value will influence how they think genetic interventions should be regulated. In this paper the author uses the taxonomy of equality put forth by Derek Parfit and applies this to the issue of genetic interventions. It is argued that telic egalitarianism is untenable and that deontic egalitarianism collapses into prioritarianism. The priority view maintains that it is morally more important to benefit the people who are worse off. Once this precision has been given to the concerns egalitarians have, a number of diverse issues must be considered before determining what the just regulation of genetic interventions would be. Consideration must be given to the current situation of the least advantaged, the fiscal realities behind genetic interventions, the budget constraints on other social programmes egalitarians believe should receive scarce public funds, and the interconnected nature of genetic information. These considerations might lead egalitarians to abandon what they take to be the obvious policy recommendations for them to endorse regarding the regulation of gene therapies and enhancements.

Correspondence to:

C Farrelly, Department of

Political Science, University

of Waterloo, 200

University Avenue,

West Waterloo,

Canada N2L 3G1:

farrelly@uwaterloo.ca

Received 30 October 2002

In revised form

10 June 2003

Accepted for publication

4 September 2003
A dvances in genetic and biological knowledge raise a number of concerns for egalitarians. The prospect of being able to directly intervene in the natural lottery of lifefor example, through genetic therapies, raises the hope that we can prevent and cure a variety of diseases. Yet concerns about who will have access to these interventions, especially genetic enhancements, have led many egalitarians to stress the threat genetic interventions pose to the value of equality. Maxwell Mehlman and Jeffrey Botkin claim that "with the possible exception of slavery, [genetic technologies] represent the most profound challenge to cherished notions of social equality ever encountered. Decisions over who will have access to what genetic technologies will likely determine the kind of society and political system that will prevail in the future". ${ }^{\prime}$ Similar concerns are expressed in the recent Nuffield Council on Bioethics' report which states: "We believe that equality of opportunity is a fundamental social value which is especially damaged where a society is divided into groups that are likely to perpetuate inequalities across generations. We recommend, therefore, that any genetic interventions to enhance traits in the normal range should be evaluated with this consideration in mind". ${ }^{2}$
The authors of From Chance to Choice: Genetics and Justice endorse two specific conclusions that should guide public policy choices in the age of genetic intervention. The first is that there is a principled presumption that genetic intervention to prevent or ameliorate serious limitations caused by disease is a requirement of justice and, secondly, that justice may require regulating conditions of access to genetic enhancements to prevent exacerbations of existing unjust inequalities. ${ }^{3}$ Walter Glannon, in Genes and Future People, goes so far as to say that genetic enhancements should be impermissible because unequal access to such interventions could undermine our belief in the importance of the fundamental equality of all people. "Allowing inequalities in access to and possession of competitive goods at any level of functioning or welfare might erode this basis and the ideas of harmony and stability that rest on it." ${ }^{4}$

In this paper I will explore some of the difficulties egalitarians will face as the prospect of successfully intervening in the natural lottery of life becomes more of a reality. The concern that genetic interventions threaten equality is often expressed by egalitarians but it is one that requires closer scrutiny. Following Derek Parfit ${ }^{5}$ I distinguish between two types of egalitariansthose who maintain that it is in itself bad if some people are worse off than others (telic egalitarians) and those that object to inequalities that are unjustly created (deontic egalitarians). I argue that the former is untenable and that the latter collapses into prioritarianism. The priority view maintains that benefits to the least advantaged should be given more weight. I then argue that a determination of the impact different regulatory frameworks of genetic interventions are likely to have on the least advantaged requires egalitarians to consider a number of diverse issues beyond those they typically consider, such as the current situation of the least advantaged, the fiscal realities behind genetic interventions, the budget constraints on other social programmes egalitarians believe should also receive scarce public funds, and the interconnected nature of genetic information. These considerations might lead egalitarians to abandon what they take to be the obvious policy recommendations for them to endorse regarding the regulation of gene therapies and enhancements.

\section{GENETIC EQUALITY}

Let us now consider the following hypothetical example as a way of bringing to the fore some of the different concerns egalitarians must consider. Imagine that Martians land in our current, genetically unequal society and bring with them 
a supply of safe and effective gene therapies and enhancements which could be distributed to all members of our society. ${ }^{*}$ Before making these interventions available the Martians request that we democratically choose one of the following policies to regulate the distribution of these technologies:

1. Ban on everything: no one will ever be able to use these therapies or enhancements.

2. Make gene therapies available to all; ban on enhancements.

3. Make gene therapies available to all; restricted access to enhancements.

4. Make gene therapies and all enhancements available to all.

Much debate takes place as people assess the advantages and disadvantages of the four policies. Those who reject the very idea of genetic intervention endorse (1) and argue that no one should be allowed to use these interventions. Those who support (2) argue that we should make gene therapies available to all to cure and prevent disease but that enhancements should be banned. Gene therapy, they argue, has morally legitimate medical uses but enhancements do not: curing disease is one thing but enhancing people's genes is another.

Those who defend (3) agree that equal access to therapies is necessary but also believe that access to some enhancements should be allowed because they can also promote legitimate medical uses. But those who defend (3) also believe that access to these enhancements should be limited. Even if everyone is disease free, or all have a minimum risk of disease, some people have genes that confer greater advantages on them (for example, make them more likely to live longer, be more intelligent, and so on) and if we permit these people to have access to enhancements this would confer on them extra advantages others could never attain. Limited access to enhancements is thus necessary, they will argue, because it will secure genetic equality. Equality, they maintain, is intrinsically valuable. The loss of extra utility that our society incurs by limiting access to enhancements for those with the best genetic profiles is outweighed by the gain we get from achieving genetic equality.

Those who defend (4) claim that individuals should be given the choice of having both therapies and enhancements. Why should those who already have the most promising genetic profiles be denied the chance to live longer and be even more intelligent just because this will mean we are unequal? The existing inequality in our genetic endowments is not unjust-it was just the result of the natural lottery of life. So if the initial unequal distribution was not unjust then how can the new, genetically more optimal yet unequal distribution be unjust if all have equal access to gene therapies and enhancements?

Those attracted to position (3), for the reasons I have mentioned, are telic egalitarians. Those attracted to position (4), for the reasons I have mentioned, are deontic egalitarians. Telic egalitarians object to a "state of affairs", namely, that some people are worse off than others through no fault of their own; whereas deontic egalitarians only object to

* To avoid complications concerning intergenerational justice let us stipulate that the interventions are somatic, and not germ line, therapies, and enhancements. Any reference to genetic intervention in this paper can be taken to mean somatic intervention. For a useful discussion of the different issues raised by somatic line and germ line modifications see chapter 8 of John Harris's Clones, Genes and Immortality. Oxford: Oxford University Press, 1998. inequalities that are unjustly created. Deontic egalitarians will not characterise the new genetically unequal but more optimal distribution as unjust because they do not believe that the measures leading to this inequality are objectionable. We shall return to this point later as it is central to the concerns raised in a society with budget constraints. But let us focus first on telic egalitarianism.

Telic egalitarians believe that inequality is in itself bad. The Martian example represents the ideal circumstances for telic egalitarians as it is a situation that allows us to achieve "genetic equality" in a way that is not susceptible to the standard levelling down objection raised against equality (however, as we shall soon see, telic egalitarianism is susceptible to a version of the levelling down objection). By making gene therapies accessible to all and limiting access to genetic enhancements, telic egalitarians will ensure at a minimum that our genetic potentials give us the best chance of falling within the normal range of functioning. But telic egalitarians may seek to adopt a more expansive programme of genetic equality. The first challenge facing telic egalitarians would be to come up with a list of the advantages/ disadvantages genes confer and which of those they believe should be equalised. It is important to bear in mind that genes do not, by themselves, necessarily confer advantages or disadvantages. Social environment, for example, plays an important role in determining whether one even develops a certain genetic disease as well as the severity of the condition. It is thus better to talk about the likelihood of advantages that our genes confer on us. The following list might be one a telic egalitarian would put forth to capture some of the potential advantages/disadvantages our genes confer that should be equalised:

- equal risk of disease;

- equal chance of living to a certain age;

- equal chance of attaining a certain level of intelligence;

- equal chance of developing certain valued physical (for example, a certain height) and behavioural traits (for example, initiative, cooperativeness).

The list could go on and on. If one believes that all of these do concern significant advantages then telic egalitarians would have to endorse equalising our genetic potentials for these things. Such a proposal would actually be consistent with the dominant position among egalitarian theories of distribution justice, the position Elizabeth Anderson calls "luck egalitarianism". ${ }^{6}$ Those who defend luck egalitarianism include Ronald Dworkin, Philippe Van Parijs, Richard Arneson, and G A Cohen. Luck egalitarians believe that inequalities in the advantages that people enjoy are just, as long as they derive from the choices people have voluntarily made; inequalities deriving from unchosen features of people's circumstances are unjust. Given that our genetic profiles are unchosen features of our circumstances then we should seek to mitigate this unfair inequality if this were possible, as it is in the Martian example. Thus telic egalitarians would endorse (3) and support a strict regulation of the relevant enhancements so that the well endowed do not exceed the level we are trying to equalise. Now of course some individuals may refuse to use certain enhancements, maybe even therapies, but telic egalitarians will not see this as a serious threat to their egalitarian vision because such inequalities could now be characterised as those stemming from the choices people have voluntarily made.

Anxious to implement their new vision of a genetically equal society, the members of this society start to consider some of the finer details of this vision when they hit some serious stumbling blocks. As Buchanan et al point out (see reference 3 at pages 79-81), there are two serious problems 
with the principle of genetic equality. Firstly, what counts as an asset is at least partly defined by the dominant cooperative framework. This means that the traits we view as valuable will inevitably change with time. If we intervene in the natural lottery of life to ensure that future generations have the same genetic potential to develop valuable traits, it may turn out that by the time they reach adulthood those traits will no longer be valued. The traits valued in an agrarian society, for example, are vastly different from those valued in highly advanced industrial societies, where computer literacy is a prerequisite for a constantly growing number of occupations. We just do not have the foresight to be able to predict what traits will or will not be valued in the future. Thus, intervening in the natural lottery in the name of equality is bound to fail to achieve what egalitarians hope it will achieve (that is, make everyone equally advantaged).

The second problem with genetic equality, argue Buchanan et al, is that "any thought of equalizing [natural] assets would almost certainly betray a failure to appreciate what might be called the fact of value pluralism (or diversity of the good)" (see reference 3 at page 80). There is no "objective list" of physical or behavioural characteristics that all reasonable people would agree are valuable, let alone the most valuable.

\section{THE LEVELLING DOWN OBJECTION TO TELIC EGALITARIANISM}

The two objections Buchanan et al raise against genetic equality are not decisive objections to that principle as one could adopt a more minimalist conception of genetic equality. One could argue, for example, that the only thing we should try to equalise is our risk of disease. Ideally, we should all have the same minimal risk of developing disease. Such an aim would not violate value pluralism, nor is the value we place on being "disease free" something which would change in time. This leads me to what I think is the decisive objection to the principle of genetic equality. The ideal of a genetically equal society might be attractive to those egalitarians who believe that equality has some intrinsic value, but it is only plausible to even contemplate such a principle in a contrived example like the Martian example (where it is possible to bring everyone up to an equally advantageous position). But this is simply not possible in the real world where there are budget constraints. Gene therapies and enhancements are not going to fall like manna from the heavens for us to just decide how to distribute them. It is common for philosophers to invoke hypothetical thought experiments to help clarify what distributive ideal they think could be publicly justified. Rawls invokes the original position and Dworkin his hypothetical auction and insurance scheme. ${ }^{78}$ These kinds of thought experiments can be helpful but they can also detract from many of the pressing issues that we face in the real world. I think this is extremely pertinent when it comes to the issue of genetic intervention. The decisions we now face are not as simple as deciding whether or not gene therapies or enhancements should be offered to all. These interventions are risky and costly. If we were presented with the option of equal access to genetic interventions that were $100 \%$ effective in the treatment of the most debilitating diseases, our decisions would be much easier to make. However, the decisions we make regarding the regulation of biotechnology will determine not only whether these technologies will ever exist, but also how long it will take for them to be successful and affordable.

Once we alter the Martian example so that we achieve genetic equality not by bringing everyone up, but by bringing everyone down to one level, we see that the telic egalitarian's claim that equality has some intrinsic value is mistaken. Imagine now that Martians land in our society and, having depleted their supply of gene therapies and enhancements helping others in distant parts of the universe, they opt for Plan B. Unfortunately for us, Plan B involves unleashing a disease that spreads across the population so that we all have the same high risk of developing the most debilitating diseases. Is there anything good about this move from inequality to equality? No. Pluralist egalitarians will of course claim that Plan B has worsened our situation as equality is not the only value they cherish (pure egalitarians believe that equality is the only value whereas pluralist egalitarians believe that equality is just one of many important values (for example, freedom and utility)). They also care about utility and in our initial, genetically unequal society we had much more utility-thus pluralist egalitarians could consistently say that they would prefer that arrangement to the new one. But that does not deflect this version of the levelling down objection. As Parfit points out, the levelling down objection undermines telic egalitarianism if there is nothing good about achieving equality by levelling down (see reference 5 at page 99). And this would be the case in the example I just described. The move to equality has not been good for anyone: everyone has had their situation worsened-even those who already had a high risk of developing disease have had their situation worsened as their loved ones now have the same high risk of dying from disease. Thus, equality cannot be intrinsically valuable.

Some have raised objections to the levelling down objection. Temkin, for example, defends non-instrumental egalitarianism against the levelling down objection. ${ }^{9}$ At the heart of the levelling down objection is what Temkin refers to as The Slogan, which subscribes to the Person-affecting Claim (see reference 9 at page 132):

\section{"The Slogan: One situation cannot be worse (or better) than another if there is no one for whom it is worse (or better)."}

Temkin provides a number of distinct arguments against the levelling down objection. To fully address his arguments would be a paper in itself (I address Temkin's arguments more fully in my unpublished work) so let me just briefly address one of his arguments: the example that appeals to Parfit's Non-Identity Problem. The example Temkin employs to illustrate that the Slogan is wrong concerns policies which involve postponing having children in order to conserve natural resources. In order for this to be applicable to our discussion of genetic equality let me slightly modify Temkin's example in the following way. Imagine that Martians land in our society and give us a fixed amount of the resources necessary to develop a fixed stock of safe and effective genetic therapies and enhancements. From this fixed stock of genetic technologies, we permit regulated access to gene therapies and enhancements to the current generation to ensure that we achieve "genetic equality" in terms of our potentials for health, vigour, and longevity (fig 1A). In this scenario all members of the current generation have the same genetic potential for living a life within the normal range of functioning. With the remaining stock of genetic technologies we could deplete them now by developing further enhancements for us to enjoy, thus raising our chances of living longer, improving our immune systems, and so on. But by doing so we would leave nothing for the next generation. Alternatively, if we conserve the remaining scarce resources we will, in a few years time, be able to convert those few resources into an abundant supply of prenatal genetic interventions. If we postpone having children until such prenatal interventions are developed we can thus ensure that 


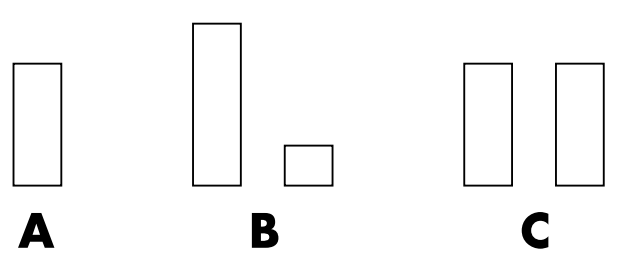

Figure 1 "Live for today" $v$ "Live for tomorrow".

the next generation will enjoy the same level of genetic advantages that we enjoy.

So we now have two options. We could adopt a "live for today policy" and deplete the genetic interventions we have thus resulting in the inequalities present in figure $1 \mathrm{~B}$, or we could agree to postpone having children for a few years until we develop the stock of prenatal genetic interventions that will permit us to provide our children with the same level of genetic advantages that we ourselves enjoy (fig $\mathrm{lC}$ ). This second policy is the "take care of tomorrow policy".

Temkin believes that most of us would maintain that we should adopt the "take care of tomorrow policy". But the Slogan cannot account for this judgement, claims Temkin. The Slogan says that B can only be worse if it is worse for someone. But Temkin argues that both the parents and children in B are better off than they would be in C. The parents enjoy greater genetic endowments in $\mathrm{B}$ than they enjoy in C. And the children in B would be worse off in C as they would not even have been born if their parents opted for the "take care of tomorrow policy". So we have a situation where we believe that one scenario (B) is worse than another (C) even though it is not worse for anyone. This, argues Temkin, undermines the Slogan and thus the levelling down objection.

There are a number of different strategies for undermining Temkin's argument. Firstly, I do not share Temkin's intuition that $\mathrm{C}$ should be adopted. Temkin just assumes that no one will object to a policy that requires people to postpone having children. Although I do believe that there are conceivable circumstances where such a policy may be justified, I do not think they apply in either my modified example or Temkin's original example. But rather than expand on this point let me focus instead on an argument that engages his example in a more direct manner.

Unlike Temkin, I believe the Slogan can account for why B is worse than C. It is worse for the parents. Temkin's example only seems plausible if we assume that the interests of the current generation are distinct from those of their children. But this is false-surely it is better for parents to have healthy children than children who will die prematurely from disease. If $\mathrm{B}$ is worse than $\mathrm{C}$ we can argue that it is worse for the parents. In the example actually used by Temkin the scarce resources are natural resources and not genetic interventions. But the Slogan can account for why a policy of "live for today" is worse than the policy of "take care of tomorrow" in that example as well. It is better for the parents to have children who will be able to feed themselves rather than to have children who will starve. Temkin believes that it is our concern for equality itself that leads us to support the "take care of tomorrow" policy. But I find his argument unconvincing. If $\mathrm{B}$ is better than $\mathrm{C}$ it is better because it is better for someone. The Non-Identity Problem does not establish non-instrumental egalitarianism.

\section{PURSUING EQUALITY IN A SOCIETY WITH BUDGET CONSTRAINTS}

Of the two versions of egalitarianism considered so far-telic and deontic egalitarianism-only the latter is a promising account of the value of equality as it is not susceptible to the levelling down objection. "On the Deontic View, our concern about equality is only a concern about what we should do" (see reference 5 at page 94). Deontic egalitarians will not view existing genetic inequalities as unjust, nor will they view the more optimal yet unequal distribution of genetic endowments in the initial Martian example as unjust. Even though genetic inequalities exist in both cases, deontic egalitarians do not view these situations as unjust because no one is denied their fair share of genetic interventions. In the current situation no one enjoys these resources and in the Martian example everyone enjoys them (even though the best endowed will enjoy greater advantages than the least endowed). Deontic egalitarians do not view the current, genetically unequal situation as unjust because there is nothing we could (justly) do to prevent this inequality (ruling out, of course, unjust eugenic policies). What is unjust, the deontic egalitarian might maintain, is a society where only the rich have access to genetic interventions. This genetically unequal situation can be deemed unjust as this new genetically unequal situation is one we could have done something about. Namely, we could have opted for a different regulatory scheme that would have improved the position of the least advantaged. It is precisely this line of argument that I want to now question.

What underlies the deontic egalitarian's claim that unequal access to genetic interventions is unjust is the belief that fairness requires that if such goods are to be given to some, they should be given to all, especially to those who most need them (such as victims of disease). Thus, what determines whether an unequal distribution is unjust is the effect upon the least advantaged. Preventable inequality that harms the least advantaged is unjust. A free market regulation of genetic interventions is unjust, critics will maintain, because it prevents the needy from having access to such interventions and thus they are harmed. Once stated like this, the deontic view collapses into what Parfit calls prioritarianism. Prioritarians maintain that benefiting people matters more the worse off these people are. In the context of genetic advantages, prioritarians will argue that we should give priority to those who are least advantaged in terms of their genetic endowments. It is concern for the welfare of the least advantaged, I believe, that really underlies the claim that the genetic revolution threatens equality.

Once we begin to address the concern for the least advantaged, and not equality itself, it is worth reminding egalitarians that the current situation is one of genetic inequality and one where the least endowed do not fare well (that is, they will die prematurely from disease). Furthermore, it is important that egalitarians recognise that in the real world (unlike in our Martian example) there are budget constraints. Although concerns for the least advantaged might lead the egalitarian to endorse a policy of equal access to genetic interventions, the viability of such a policy will depend on budget constraints. Given the other commitments egalitarians may also endorse (for example, equal opportunities in education, a right to decent health care in general, and so on) a determination of the just allocation of public funds for such programmes must take into consideration the costs and usefulness of each. Genes are just one factor among many that influence our level of wellbeing-a determination of the amount of public resources we should allocate to pursuing genetic manipulation must consider the fiscal constraints on other important programmes.

Consider, for example, the difficulties an egalitarian faces if presented with the following statement: (1) "the regulations necessary to ensure that gene therapies and some enhancements are distributed according to need, and not according to ability to pay, would result in these technologies never existing". 
One could imagine a number of factors being brought into play to explain why this might be the case. Biotechnology is a multibillion dollar industry. The severe limits on gene patenting required to ensure we pursue a policy of equal access to interventions could conceivably undermine the investment necessary to make effective treatments a reality. Given the already diverse demands on scarce public funds for other important programmes, we might not have enough available public funds to make these interventions a reality. Or, perhaps we could make equal access to these treatments a reality but only by abandoning our commitment to other important public funded programmes, such as education and health care in general.

If the egalitarian is presented with these considerationsones that we face in the real world-then what would they think about pursuing a principle of equal access to genetic interventions? They might think that they were naïve in letting their egalitarian intuitions blur their judgement about how successfully they could pursue equality in this instance. If pursuing equality brings no utility then what is the point of pursuing equality? Some egalitarians might say that, if statement 1 is true, then we should not introduce genetic interventions at all. But such a conclusion need not follow. Deontic egalitarians and prioritarians maintain that we ought to aim for equality only when doing so is for some moral reason beyond equality itself, like benefiting the worse off. But in this scenario we do not benefit anyone. Furthermore, some of the genetically least advantaged would have been better off if we had permitted limited private availability of genetic interventions. The rich, like the poor, are also susceptible to disease. Is it better that we deny these individuals the possibility of being cured of disease if everyone in our society (the world?) cannot be offered such a service?

Imagine now that it turns out that statement 1 was false. It was propaganda circulated by private biotech firms. We are now given the following true information: (statement 2) "the regulations necessary to ensure that gene therapies and some enhancements are distributed according to need, and not according to ability to pay, would result in bringing these into existence as effective treatments in 10 years". Statement 3: "the regulations necessary to ensure that gene therapies and some enhancements are distributed according to need, and not according to ability to pay, would result in such treatments being available to all who need them in 20 years".

Given this new information the egalitarian might feel better about pursing a principle of equal access to genetic interventions. Clearly there are now benefits if statements 2 and 3 are true. But what if a different arrangement would confer even greater benefits on the worse off? Consider the difficulties the deontic egalitarian and prioritarian will face if presented with the following information: (statement 4) "if the regulations concerning gene therapies and some enhancements were those most conducive to profitability then these treatments would exist as effective treatments in five years and would be affordable to all in 10 years". Furthermore: (statement 5) "if all enhancements, as well as therapies, were regulated in this way then effective and affordable gene therapies would be available to all in five years".

Faced with this information will the egalitarian abandon a principle of equal access to genetic interventions in favour of a free market regulation of genetic information and technologies? Perhaps a pure egalitarian would not. It is better, they might argue, that all have to wait 20 years before effective and affordable treatments are available than to permit only the rich to enjoy the majority of the benefits of these technologies for a few years. But I think such a response would strike most of us as perverse-think of the thousands of children born with genetic disorders we could have helped; think of the thousands of lives we could have prolonged by remedying various kinds of cancer. The egalitarian who maintains that it is better to endure all of this human suffering rather than permit the rich to translate their extra wealth into better genetic profiles is absurd. If we are prioritarians then we will opt for the regulatory framework that maximises the prospects of the least advantaged. An arrangement that permits genetic interventions to be available to the least advantaged sooner rather than later is, other things being equal, a more desirable arrangement.

Perhaps our egalitarian might respond by arguing that other things will not be equal. Unequal access to genetic interventions might result in a situation where the least advantaged become a "genetic underclass". But what, exactly, does this mean? How long would it take for such an underclass to be formed? And is there nothing we could do-short of banning access to genetic interventions-to prevent such an underclass being created (for example, prohibiting genetic discrimination)? These, and many other questions, must be answered. It is also worth emphasising that we already have a situation of genetic inequality in the current state of affairs, so we need to know how much more disadvantaged victims of disease would be once they are members of the genetic underclass, as opposed to people who just die prematurely from disease. I am not suggesting that the concern about creating a genetic underclass should not be taken seriously, but this concern needs to be more fully developed than simply asserting, as many egalitarians do, that unequal access to genetic interventions undermines equality.

Statement 5 raises a very important issue that the egalitarian must consider. Although many egalitarians might object to the thought of the rich having access to further advantages in the forms of certain genetic enhancements that would allow them to live longer and/or have stronger immune systems, for example, they should bear in mind that such advantages need not be objectionable if they confer the greatest possible benefits on the worst off. Now of course it might turn out that in reality this is simply not the case, but this prospect is not as implausible as one might initially think if one reflects on the interconnected nature of the information at issue. It is not inconceivable that, through the knowledge gained by pursuing certain enhancements we might come to have a better understanding of how to treat certain genetic diseases. Better knowledge of the ageing process and our immune system is bound to confer some benefits to our understanding of how certain diseases develop.

\section{CONCLUSION}

Egalitarians must consider a diverse myriad of issues as they contemplate how biotechnology should be regulated. Given the diverse commitments egalitarians endorse (equal opportunities in education, a right to decent health care in general, and so on) a determination of the just allocation of public funds for such programmes and for pursuing genetic interventions must take into consideration the utility generated by each programme and the costs involved in making these utilities a reality. Genes are just one factor among many that influence our level of wellbeing and thus a determination of the amount of public resources we should allocate to pursuing genetic manipulation must consider the budget constraints on other important programmes.

Given the strains on existing social programmes, egalitarians might decide that it is best to invest scarce public funds in other programmes which will confer greater advantages on the least advantaged. But then egalitarians must determine what the likely consequences of permitting limited private 
availability of genetic interventions will be for the worse off. Those who claim that such a policy would lead to the formation of a genetic underclass make a number of assumptions we can question. Assuming such fears are both coherent and tangible, we can ask whether such an underclass would be created before the prices of genetic interventions would fall to a level that would make their being made available to all possible. Furthermore, would permitting limited private availability of genetic interventions in conjunction with a ban on genetic discrimination not help prevent the formation of a genetic underclass?

Egalitarians must consider the long term consequences of the different regulatory schemes available for biotechnology and weigh the potential benefits to utility against the potential losses to equality. The latter ought to be measured by the harm incurred upon the least advantaged. Given that the current, genetically unequal situation we have is one where they will die prematurely from disease, we must be weary of the charge that the genetic revolution will undermine the value of equality. If, as I have argued in this paper, what underlies a concern for equality is a concern for the least advantaged then we should not object to inequalities that benefit the least advantaged. The diverse considerations
I have emphasised in this paper should prove sufficient for us to inform the egalitarian that their commitment to a principle of equal access to genetic interventions, although well intended, is not necessarily the correct recommendation, nor is it very useful. Egalitarians must give these issues more reflection if they are to endorse policy recommendations that will truly benefit the least advantaged.

\section{REFERENCES}

1 Mehlman M, Botkin J. Access to the Genome: The Challenge to Equality. Washington, DC: Georgetown University Press, 1998:6.

2 Nuffield Council on Bioethics. Genetics and Human Behaviour: the Ethical Context. London: Nuffield Council on Bioethics, 2002, paragraph 13.48.

3 Buchanan A, Brock D, Daniels N, et al. From Chance to Choice: Genetics and Justice. Cambridge: Cambridge University Press, 2000:101.

4 Glannon W. Genes and Future People, Boulder, Col. : Westview Press, 2001:100.

5 Parfit D. Equality or Priority? In: Clayton, Williams, eds. The Ideal of Equality. Basingstoke: Palgrave, Macmillan, 2000.

6 Anderson E. What is the point of equality? Ethics 1999:99:287-337.

7 Rawls J. A Theory of Justice. Cambridge, MA: Harvard University Press, 1971.

8 Dworkin R. Sovereign Virtue. Cambridge, MA: Harvard University Press, 2000.

9 Temkin L. Equality, Priority, and the Levelling Down Objection. In: Clayton, Williams, eds. The Ideal of Equality. Basingstoke: Palgrave, Macmillan, 2000 